\title{
EVALUATION OF ANTIBACTERIAL EFFECT OF A NEW ROOT CANAL IRRIGATING FORMULA OF SALVADORA PERSICA ROOTS NANOPARTICLES. AN IN VITRO STUDY
}

\author{
Moatazbellah A. Alkhawas*, Rehab Abdelmonem** and Mohammed E Rokaya ****
}

\begin{abstract}
Aim: The study was done to evaluate the antibacterial effect of a new formula of Salvadora persica roots Nanoparticles as compared to sodium hypochlorite irrigating solution. Methods: A total of 20 recently extracted single-rooted, with single root canal were selected to be used in the study. Decapitation of the selected teeth for $18 \mathrm{~mm}$ length standardization was done. The root canals were initially instrumented using manual instrumentation till reach file size 25 for apical preparation. Sterilization of the samples was done using gamma rays. Following sterilization, the samples were divided into two groups $(n=10)$ according to the tested irrigating solution used as follow; Group H: For Salvadora persica roots nanoparticles. Group S: For 2\% sodium hypochlorite. The chemo-mechanical preparation was accomplished using Revo-S rotary system in a crowndown technique with the file sequence that was recommended by the manufacturers. Pre and postirrigation counting of the E. Fecalis was done by determining the Colony Forming Unit. Results: The highest mean value of percentage changes in bacterial reduction was found in (Group S) (95.99\%) and the least bacterial reduction percentage was found in (Group H) (82.83\% with no statistically significant difference between both groups (P-value $=0.068)$. Conclusion: Under the condition of this study, the new formula of Salvadora persica roots nanoparticles is a promising irrigating solution of herbal origin instead of the synthetic irrigating solution.
\end{abstract}

KEY WORDS: Salvadora persica, antibacterial, nanoparticles, sodium hypochlorite, Irrigation.

\section{INTRODUCTION}

Disinfection of the entire root canal system including the elimination of all microorganisms and their by-products represents a big challenge to obtain successful root canal treatment. Among microorganisms, Enterococcus Fecalis Bacteria (EF) is one of the main causative microorganisms in pulp and periapical infection ${ }^{(1,2)}$. Elimination of such microorganisms can be achieved using the chemo-mechanical preparation of the root canal system $^{(3)}$.

\footnotetext{
* Associate Professor of Endodontics, Faculty of Dental Medicine, Al-Azhar University, Cairo, Egypt.

** Associate Professor of Pharmatheuticals, Faculty of Pharmacy, MSA, Egypt.

*** Lecturer of Endodontics, Faculty of Dental Medicine, Al-Azhar University (Assuit Branch), Egypt.
} 
Regarding irrigation of the root canal system, the use of natural products and medicaments derived from medicinal plants and herbs has markedly increased in dentistry to overcome the chemosynthetic nature of the traditional irrigating solutions $^{(4)}$. Salvadora persica roots is one of the most beneficial herbs in dental field that has been scientifically proven to have strong antibacterial effect due to its active ingredients (B-sitosterol, Benzyl-isothiocyanate, Elemental sulfur, Saponin Tannic acid, Resin, Trimethylamine, Alkaloid, Chlorine, Fluoride, silica, Sodium bicarbonate, Chlorides) ${ }^{(5,6)}$.

On the other hand, the introduction of nanotechnology has been advocated to improve the bactericidal effect in addition to the physical and chemical properties of the irrigating solutions. This can be done using the nanotechnology by converting their solid forms to the smallest nanoparticles ${ }^{(7)}$. Additionally, nanoparticles powder of Salvadora persica roots achieves the maximum solubility of its active ingredients increasing its bactericidal effect $^{(8)}$. However, little research has been done to evaluate the antibacterial effect of Salvadora persica roots in compared to sodium hypochlorite irrigating solution.

\section{MATERIALS AND METHOD}

\section{Preparation of the samples}

A total of twenty recently extracted singlerooted, with a single root canal and root curvature ranged from 0-30 degree according to schlider technique ${ }^{(9)}$ were selected to be used in this study. Following preoperative radiographic examination of the collected teeth to exclude any tooth abnormalities, such as pulp stones or teeth with root cracks and/or fractures, the root surfaces of the selected teeth were planned with an ultrasonic scaler (Suprasson P5 Booster, Satelec, France) to remove any hard deposits and soft tissue remnants on the root surfaces. Decapitation of the selected teeth for $18 \mathrm{~mm}$ length standardization using a diamond cylindrical stone mounted in a highspeed handpiece (PANA AIR, NSK, Japan) under water coolant was done. The adjusted samples were stored in normal saline at room temperature until the time of use. Canal patency and working length determination were established using a size $15 \mathrm{~K}$ file (Dentsply Maillefer, Ballaigues, Switzerland). The root canals were initially instrumented using manual instrumentation till reach file size 25 for apical preparation.

\section{Isolation and growing of the E. Fecalis Bacteria (EF)}

Using extracted carious teeth, facultative $E$. Fecalis Bacteria (EFB) was collected for isolation of EFB using brain heart infusion medium (Microbiology \& Fungi Research Center, Al-Azhar University). This is followed by growing of EFB colonies in $100 \mathrm{ml}$ nutrient broth media in sterile glass flask capped with a cotton plug. The glass flask containing bacteria was preserved in an incubator (Incubator in 08877433 Made in Italy) for 72 hours to allow for bacterial growth.

\section{Colonization of the EF in the samples}

Following serialization of the samples using gamma rays (Egyptian Atomic Energy Authority), the colonized E. Fecalis bacteria were carried to the sterile samples using a microbiological micropipette to carry three microns of the liquid that contain $\mathrm{EF}$ bacteria in nutrient broth media for colonization of the E. Fecalis bacteria in the samples. Three microns of the suspension containing E. Fecalis was injected into each sample using the microbiological micropipette with sterile disposable plastic tip for each sample. Refreshing the canal of each sample with nutrient broth media every 2-3 days was done to allow for bacterial growth.

\section{Pre-irrigation counting of the colonized bacteria}

After 2 weeks of bacterial colonization inside the samples, a previously sterile plastic standard 
dandruff tube was used to carry the suspension containing E. Fecalis from inside the root canal of each sample. Bacterial counting of this suspension was done to determine the pre-irrigation counting of E. Fecalis using standard, viable, plate counting method for counting the viable EFB by determining the Colony Forming Unit (counting at Microbiology \& Fungi Research Center, Al-Azhar University).

\section{Grouping of the samples}

The samples were divided into two groups (ten samples for each group) according to the tested irrigating solution used as follow; Group H: Samples irrigation using a new irrigating formula of Salvadora persica roots nanoparticles. Group S: Samples irrigation using 2\% sodium hypochlorite (Prime Dental Products Pvt. Ltd. India) irrigating solution.

\section{Preparation of new irrigating formula of Salva- dora persica roots nanoparticles}

The previously collected small sticks of Salvadora Persica roots (Arrack tree roots, Miswak) were sun dried for 10 days. The dried Salvadora Persica roots were cut to small pieces and were grounded to the smallest particle powder (Nanoparticles less than 1 micron) using milling machine (Photon Nano milling machine, Germany). The prepared Nanoparticles powder of Salvadora Persica roots was stored in sterile and tightly packed bottles till the time of use.

One hundred gram of the previously prepared Nanoparticles powder of Salvadora Persica roots was mixed with two hundred $\mathrm{ml}$ distilled water and was shacked well for preparation of the aqueous solution of Salvadora Persica Nanoparticles. This aqueous solution was reserved in sterile, tightly sealed, glass bottle till the time of paste preparation.

\section{Chemo-mechanical preparation of the samples}

The root canals were instrumented using Revo-S (Micro-Mega, France) rotary system for a crowndown technique using the file sequence $\mathrm{SC} 1, \mathrm{SC} 2$, SU, AS30, AS35 and AS40 as a master apical file. The Revo-S files were mounted on a contra-angle handpiece that was attached to a torque-limiting motor (Dentsply Maillefer, Ballaigues, Switzerland) at a speed of $300 \mathrm{RPM}$ and torque $(0.8 \mathrm{~N})$ as recommended by the manufacturer. Irrigation of the root canals was done between subsequent files using $2 \mathrm{ml}$ of the tested irrigating solutions according to each group. The tested irrigating solution was delivered into the root canals using 27 gauge needle tip, $25 \mathrm{~mm}$ in length that was attached to the MaxI- probe irrigating syringe (DENTSPLY Maillefer, USA) within 1-2 mm of the working length.

\section{Post-irrigation counting of Enterococcus Fecalis Bacteria}

The post-irrigation counting of the viable bacterial colonies of EF was done using the same technique and restrictions for pre-irrigation counting of bacteria using standard, viable, plate counting method for counting the viable EFB by determining the Colony Forming Unit (CFU).

\section{Statistical analysis of the data}

The mean and standard deviation values were calculated for each group. Data were explored for normality using Kolmogorov-Smirnov and Shapiro-Wilk tests and showed parametric (normal) distribution. Independent sample t-test was used to test the difference between two non-related samples. Paired sample t-test was used to test the difference between two related samples. The significance level was set at $P \leq 0.05$. Statistical analysis was performed with IBM ${ }^{\circledR}$ SPSS $₫$ Statistics Version 20 for Windows.

\footnotetext{
* Collected from Makahmokaramah, KSA.
} 


\section{RESULTS}

The mean values, standard deviation, P-values, and the mean percentage changes in bacterial reduction when comparing between group $\mathrm{S}$ and Group $\mathrm{H}$ before and after bacterial reduction were presented in Fig. $(1,2)$, and Table (1).

The results of pre-irrigation bacterial counting of both groups showed the highest mean value of bacterial count in Salvadora persica irrigation group (Group H) $\left(23.42 \times 10^{4} \pm 15.67 \times 10^{4}\right)$ while the least mean value of bacterial count was found in sodium hypochlorite irrigation group (Group S) $\left(20.61 \times 10^{4}\right.$ $\left.\pm 5.23 \times 10^{4}\right)$ with no statistically significant difference between both groups ( $\mathrm{P}$ Value $=0.597$ ).

The results of post-irrigation bacterial counting of both groups showed the highest mean value of bacterial count in Salvadora persica irrigation group $\left(3.23 \times 10^{4} \pm 3.99 \times 10^{4}\right)$ while the least mean value of bacterial count was found in sodium hypochlorite irrigation group $\left(0.75 \times 10^{4} \pm 0.99 \times 10^{4}\right)$ with no statistically significant difference between both groups ( $\mathrm{P}$ value $=0.073$ ).

On another hand, there was a statistically significant difference between pre-irrigation and post-irrigation bacterial counting In Group $\mathrm{S}(\mathrm{P}=$ 0.001), and In Group H ( $\mathrm{p}=0.002)$.

The highest mean value of percentage changes in bacterial reduction was found in (Group S) $(95.99 \%)$ and the least bacterial reduction percentage was found in (Group H) $(82.83 \%$ with no statistically significant difference between both groups $(\mathrm{P}-\mathrm{value}=0.068)$.

TABLE (1) The mean values, standard deviation, P-values, and the mean $\%$ changes in bacterial reduction when comparing between group $\mathrm{S}$ and Group $\mathrm{H}$ before and after bacterial reduction.

\begin{tabular}{|c|c|c|c|c|c|c|}
\hline \multirow{2}{*}{ Variables } & \multicolumn{2}{|c|}{ Pre irrigation count } & \multicolumn{2}{|c|}{ Post irrigation count } & \multirow{2}{*}{ P-value } & \multirow{2}{*}{$\begin{array}{l}\text { Mean percentage } \\
\text { changes in bacterial } \\
\text { reduction }\end{array}$} \\
\hline & Mean & SD & Mean & SD & & \\
\hline Group S & $20.61 \times 10^{4 a}$ & $5.23 \times 10^{4}$ & $0.75 \times 10^{4} \mathrm{~b}$ & $0.99 \times 10^{4}$ & $0.001 *$ & $95.99 \%^{c}$ \\
\hline Group H & $23.42 \times 10^{4}$ a & $15.67 \times 10^{4}$ & $3.23 \times 10^{4 b}$ & $3.99 \times 10^{4}$ & $0.002 *$ & $82.83 \%^{c}$ \\
\hline P-value & \multicolumn{2}{|c|}{$0.597 \mathrm{~ns}$} & \multicolumn{2}{|c|}{$0.073 n s$} & & $0.068 \mathrm{~ns}$ \\
\hline
\end{tabular}

Mean values with different letters in the same column indicate statistically significant difference $\quad$ *; significant $(p<0.05)$ ns; non-significant ( $p>0.05)$.

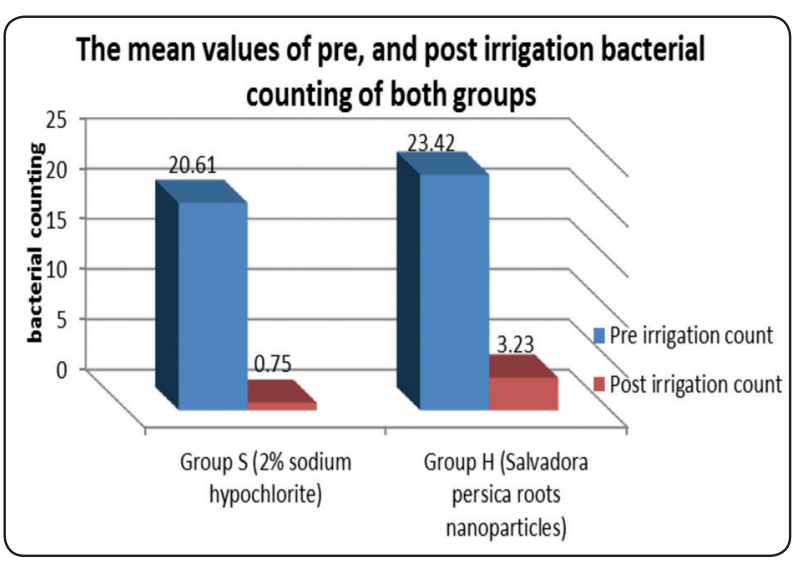

Fig. (1) Histogram showing the mean differences of bacterial count in the test groups.

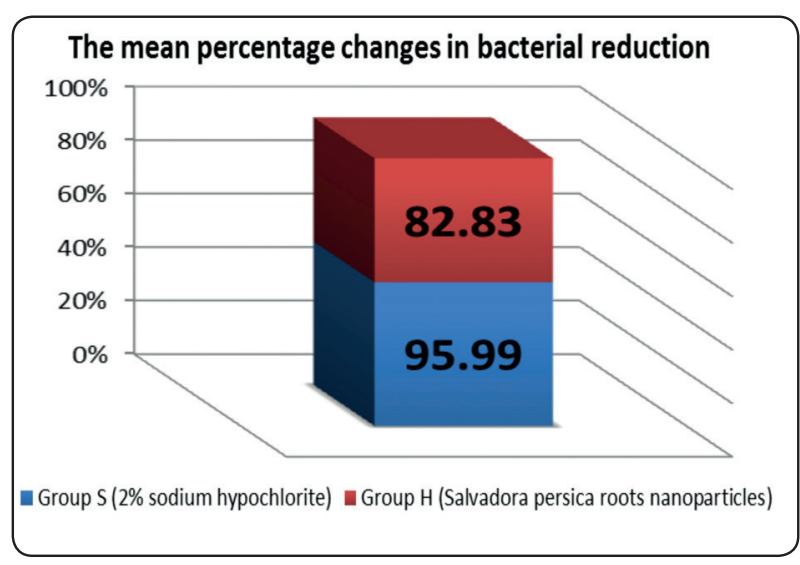

Fig. (2) Histogram showing the percentage changes in the bacterial reduction in both groups. 


\section{DISCUSSION}

The use of nanoparticles as antimicrobial agents has recently attracted considerable attention in the medical field as a result of their superior antibacterial properties compared with those of other antimicrobial agents together with a low potential to produce microbial resistance ${ }^{(10)}$. The antimicrobial activity of nanoparticles against different microorganisms differs from that of its original bulk state and may vary according to the different types of nanoparticles ${ }^{(11)}$.

There is promise in the use of different types of nanoparticles as antimicrobial agents especially against persistent endodontic pathogens such as $E$. faecalis $^{(12)}$.

E. faecalis is one of the most common bacterial species that can persist in treated root canals and are resistant to traditional antibacterial agents ${ }^{(13)}$. The antibacterial activity was directly proportional to the concentration of the test solutions ${ }^{(14)}$.

The irrigating solution must combine maximum antimicrobial action with minimum toxicity, physical and chemical properties associated with a feasible cost to the professional ${ }^{(15)}$. The major advantages of using herbal alternatives are easy availability, cost-effectiveness, increased shelf life, low toxicity, and lack of microbial resistance reported so far ${ }^{(16)}$.

The present study was aimed to evaluate the antibacterial effect of a new root canal irrigating formula of Salvadora persica roots nanoparticles against $2 \%$ sodium hypochlorite irrigating solution.

The results of our study illustrated that the highest mean value of percentage changes in bacterial reduction was found in Group S (2\% sodium hypochlorite) by $95.99 \%$ and the least bacterial reduction percentage was found in Group $\mathrm{H}$ (Salvadora persica roots nanoparticles) by $82.83 \%$ with no statistically significant difference between both groups (P-value $=0.068)$.

The reason for these results may be due to
Salvadora persica extracts glycosides, sterols, terpenes, flavonoids, tannins, and alkaloids. The antimicrobial activity of tested medicinal plant can be attributed to any of these constituents ${ }^{(17)}$.

Farooqi et al. isolated benzyl-isothiocyanate from Salvadora persica root and they claimed to have found saponins along with tannins, silica, a small amount of resin, trimethylamine, and alkaloidal constituents. While Ray et al. isolated $\beta$-sitosterol, m-anisic acid, and salvadourea. Lewis and Elvin-Lewis report a high content of minerals in the $\operatorname{root}^{(18)}$.

Wolinsky and Sote ${ }^{(19)}$ by isolation of the active ingredient from Salvadora persica, found that the limonoid had a great antimicrobial activity against various Gram-positive and Gram-negative microorganisms.

The results of this study coincide with the results of other studies that proved the antimicrobial effect of Salvadora persica in which the antimicrobial activity of Miswak extract has been reported by some researchers. Al-Sabawi et al. ${ }^{(20)}$ reported significant antimicrobial effect at $15 \%$ alcoholic Miswak extract, however, this was not significantly different from sodium hypochlorite and chlorhexidine. Darout et al. ${ }^{(21)}$ reported that Miswak extract had an antibacterial activity against Streptococcus faecalis, Pseudomonas aeruginosa, and Staphylococcus aureus, which may be due to its nitrate content.

On another hand, aqueous and methanol extracts of Salvadora persica were investigated by Firas et al. (22) for its antimicrobial activities against seven isolated oral pathogens. The aqueous extract inhibited all isolated microorganisms more efficient than the methanol extract.

In another study, Al-Salman et al. ${ }^{(23)}$ revealed that $10 \%$ water extraction of Salvadora persica is an effective antimicrobial agent when utilized clinically as an irrigant in the endodontic treatment of teeth with necrotic pulps. 


\section{CONCLUSIONS}

The use of herbal alternatives as a root canal irrigant might prove to be advantageous considering the several undesirable characteristics of $\mathrm{NaOCl}$.

\section{RECOMMENDATION}

Further research is needed to conclusively recommend herbal solutions as a root canal irrigant.

\section{REFERENCES}

1- Gomes B, Pinheiro E. Enterococcus faecalis in dental root canals detected by culture and by polymerase chain reaction analysis. Radiol Endod j. 2006; 102:247-53.

2- Shingare P, Chaugule V. Comparative evaluation of antimicrobial activity of Miswak Propolis, Sodium hypochlorite and saline as root canal irrigants by microbial culturing and quantification in chronically exposed primary teeth. GERMS 2011; 1:12-21.

3- Vianna M, Gomes B. In vitro evaluation of the susceptibility of endodontic pathogens to calcium hydroxide combined with different vehicles. Braz Dent J 2005; 16:175-80.

4- Coates A, HuY, Bax Ret al. The future challenges facing the development of new antimicrobial drugs. Nat Rev Drug Discov 2002; 1: 895-901.

5- Darout, Christy A, Skaug N, Egeberg P. Identification and quantification of some potentially antimicrobial anionic components in miswak extract. Indian J Pharmacol.2000; 32:11-14

6- Sarougekasi, Christy. Identification and Quantification of some potentially Anionic Components in Miswak. Ghazanfar SA 2007; 32: 11.

7- Akaptta, Es. Effects of endodontic procedures on the population of viable microorganisms in the infected root canal. J Endod. 1976; 2:369-73.

8- Margarida Coelho Abrantes3, Carrilho, Effect of calcium hydroxide as intracanal medication on the apical sealing ability of mineral trioxide aggregate (MTA). Scand J Dent Res. 1981; 89:321-8.

9- Schneider S.W. A comparison of canal preparations in straight and curved root canals. Oral Surg Oral Med Oral Pathol 1971; 32: p. 271-5.

10- Seil JT, Webster TJ. Antimicrobial applications of nanotechnology: methods and literature. International Journal of Nanomedicine 2012; 7:2767.

11- Beyth N, Houri-Haddad Y, Domb A, Khan W, Hazan R. Alternative antimicrobial approach: nano-antimicrobial materials. Evidence-Based Complementary and Alternative Medicine 2015; 2015:1-16.

12- Ibrahim A I O, Moodley D S, Petrik L, Patel N. Use of antibacterial nanoparticles in endodontics. SADJ April 2017; 72 ; (3) $105-112$.

13- Pinheiro ET, Gomes BP, Ferraz CC, et al. Microorganisms from canals of root-filled teeth with periapical lesions. Int Endod J 2003; 36:1-11.

14- Prabhakar J, Senthilkumar M, Priya M.S, Mahalakshmi K, Sehgal P.K, Sukumaran V.G. Evaluation of Antimicrobial Efficacy of Herbal Alternatives (Triphala and Green Tea Polyphenols), MTAD, and 5\% Sodium Hypochlorite against Enterococcus faecalis Biofilm Formed on Tooth Substrate: An In Vitro Study. J Endod. ; 36; 1:2010.

15- Ferreira CM, Bonifacio KC, Froner IC, Ito IY. Evaluation of the antimicrobial activity of three irrigating solutions in teeth with pulpal necrosis. Braz Dent J. 1999; 10(1): 15-21.

16- Abascal K, Yarnell E. Herbs, and drug resistance. Part 2-clinical implications of research on microbial resistance to antibiotics. Altern Complementary Therapies 2002; 8:284-90.

17- Anthoney Swamy T, Lasiti T. Timothy Phytochemical and antibacterial evaluation of ethanolic extract of Salvadora persica root extract against selected microorganisms. International Journal of Bioassays 4.12 (2015): 4658- 66.

18- Khatak M, Khatak S, Siddqui A.A, Vasudeva N, Aggarwal A, Aggarwal P. Salvadora persica. Pharmacognosy Reviews 2010;4 (8):209- 14.

19- Wolinsky LE, Sote EO. Isolation of natural plaque inhibiting substances from Nigerian chewing sticks. Caries Res. 1984; 18: 216-225.

20- Al-Sabawi NAK, Al Sheikh Abdal AKK, Taha MY. The antimicrobial activity of Salvadora Persica solution (Miswak- Siwak) as root canal irrigant (A comparative study). University of Sharjah Journal of Pure \& Applied Sciences 2007; 4: 69-91.

21- Darout IA, Christy AA, Skaug N, Egeberg PK. Identification and quantification of some potentially antimicrobial anionic components in Miswak extract. Indian J Pharmacol 2000; 32: 11-14.

22- Firas A., AL-Bayati, D. Khudir and Sulaiman. In vitro antimicrobial activity of Salvadora persica L. extracts against some isolated oral pathogens in Iraq. Turk. J. Biol., 2008; 32: 57-62.

23- Al- Salman TH, Al- Shaekh Ali MGh, Al- Nu'aimy OM. The antimicrobial effect of water extraction of Salvadora persica (Miswak) as a root canal irrigant. Al-Rafidain Dent J. 2005; 5(1): 33-36. 